\title{
Cooling Rate Influence on Corrosion Resistance of a A383 Aluminum Alloy in Contact with E10, E30 and E100 Bio-Ethanol
}

\author{
M. Santos-Beltrán ${ }^{\mathrm{a}, \mathrm{b}}$, A. Santos-Beltrán ${ }^{\mathrm{a}, \mathrm{c}}$, V. Gallegos-Orozco ${ }^{\mathrm{a}, \mathrm{b}}$, R. Martínez-Sánchez ${ }^{\mathrm{c}}$, F. Paraguay- \\ Delgado $^{c}$, C . Rodríguez-González ${ }^{\mathrm{b}}$
}

${ }^{a}$ Universidad Tecnológica Junta de los Ríos, Av. Independencia No. 5007, C. P. 31050. Chihuahua, Chih. México

${ }^{\mathrm{b}}$ Universidad Autónoma de Cd. Juárez (UACJ), Av. Del Charro No. 610 Cd. Juárez, Chih., México

${ }^{\mathrm{c} C e n t r o ~ d e ~ I n v e s t i g a c i o ́ n ~ e n ~ M a t e r i a l e s ~ A v a n z a d o s ~(C I M A V), ~ M i g u e l ~ d e ~ C e r v a n t e s ~ N o . ~ 120, ~ C . P .31109, ~}$ Chihuahua, Chih., México

Recently, bio-fuel has been promoted worldwide as an alternative energy to fossil fuel in transport applications according to the global policy to reduce greenhouse gas emissions and consumption of crude oil. Among the bio-fuels available, bio-ethanol is an attractive candidate with the advantages of a huge resource for production, simple fabrication process and the utilization of existing techniques and facilities without the need to construct new infrastructures. Moreover, bio-ethanol blended gasoline fuels can reduce the fuel cost of automotive to approximately 1-3\% with increasing ethanol content by E10E30 (ethanol vol. \%) compared to regular unleaded gasoline [1-3]. Attempts to increase the ethanol content from E10 to E80 or higher can impose an unpredictable non-linear corrosive effect on aluminum alloys.

Aluminum alloy A383 was melted at $740^{\circ} \mathrm{C}$ under an argon inert gas atmosphere. Three different molds were used to study the cooling rate during the casting solidification: mold steel, graphite mold and sand mold. To verify the cooling rate measurements a type $\mathrm{K}$ thermocouple attached to the mold was used. Each individual solidified piece from the different molds (sand graphite and steel) were cut at $20 \mathrm{~mm}$ in diameter and $10 \mathrm{~mm}$ thick and subjected to immersion corrosion tests at room temperature and isolate from the surroundings. The corrosion medium used was a fuel mixture of commercial unleaded gasoline and anhydrous bio-ethanol with a purity of $99.9 \%$. The fuel mixture was 10, 30, $100 \mathrm{vol}$. \% of ethanol content. The aluminum alloy specimen was exposed to the fuel-ethanol mixture during $2000 \mathrm{~h}$. Also an aluminum die-cast alloy A383 samples (which is commonly used in automotive parts in contact with ethanol) were prepared and subject to corrosion process under the same conditions for comparison purposes. After the corrosion tests, the microstructure of the samples corroded surface was observed by optical microscopy and scanning electron microscopy (SEM) and analyzed by energy dispersion spectroscopy (EDS).

It was found that the cooling casting rate had an important influence on the secondary dendrite arm spacing (SDAS) formation. According to the results, the corrosion is in direct proportion to the rate of cooling casting, for all the samples was observed that at high cooling rate the corrosion degree increased. The solidified sand casting mold samples showed the lowest rate of cooling, the largest SDAS and the lowest degree of corrosion. On the other hand the automotive aluminum die-cast alloy A383 sample showed small SDAS and the greater degree of corrosion. Also the biofuel corrosivity increases 
with the amount of ethanol, for samples with $10 \%$ vol. ethanol (E10), practically no corrosion was observed, for samples at 30\% vol. ethanol (E30) a small change in coloration was observed without material loss, however at 100\% vol. ethanol (E100) showed regions with high corrosion (see Fig.1). Fig. $2 \mathrm{a}$ and $2 \mathrm{~b}$, show the SEM image of the aluminum alloy A383 of the solidified sand mold sample and the automotive aluminum die-cast alloy A383 sample after the corrosion test respectively. The image also shows the EDS analysis that shows the presence elements into the Al matrix. The automotive aluminum die-cast alloy A383 sample showed the higher amount of oxygen (24.62 wt. \% O).

\section{References}

[1] Charles MB, Ryan R, Ryan N, Oloruntoba R. Public policy and biofuels: the way forward Energy Policy 2007;35:5737-46.

[2] Yacobucci BD, Schnepf R. Selected issues related to an expansion of the renewable fuel standard (RFS). CRS report for Congress (US): Congressional Research Service; 2008. Report No.: RL34265. [3] Hoekman SK. Biofuels in the U.S. Challenges and opportunities. Renewable Energy 2009; 34:1422.

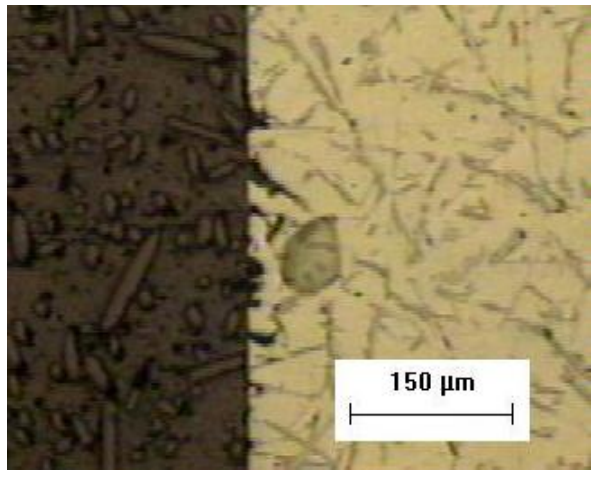

a)

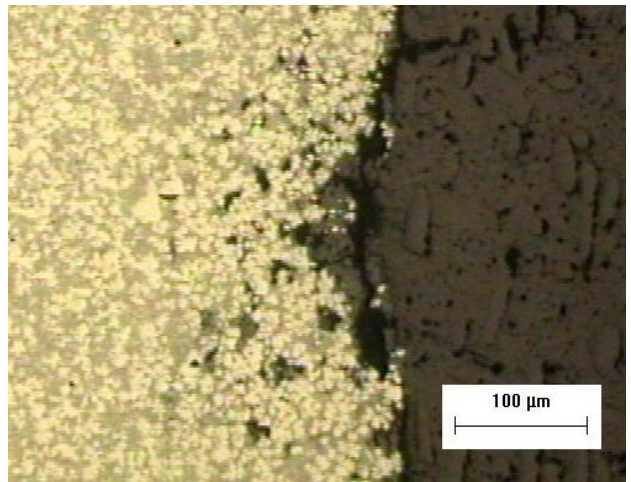

b)

Fig. 1 Analysis pit depth of an optical microscope, a) solidified sand mold E100 sample, b) automotive aluminum die-cast alloy A383 E100 sample.

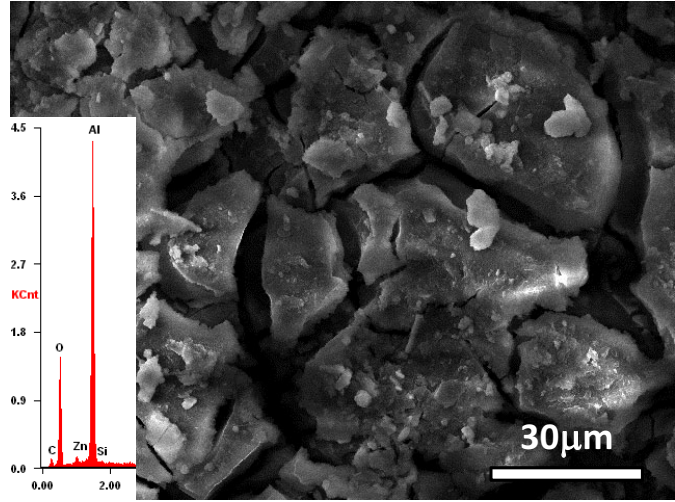

a)

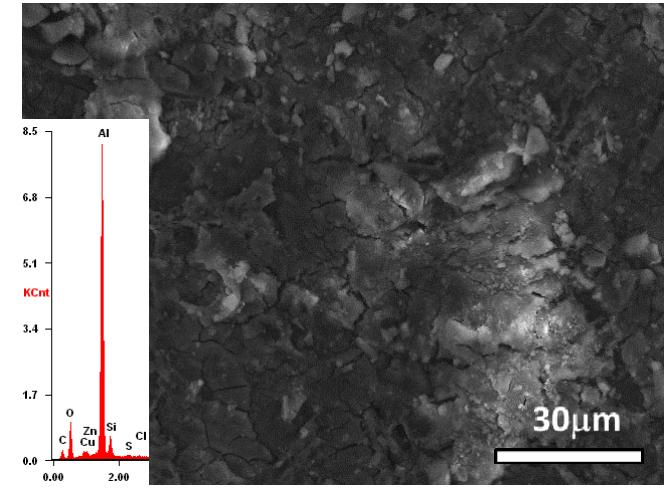

b)

Fig. 2. SEM image and EDS analyses of a) automotive aluminum die-cast alloy A383 sample and b) sand mold sample. 